\title{
ORIGINAL
}

\section{DETERMINAÇÃO DE PERIGOS E PONTOS CRÍTICOS DE CONTROLE PARA IMPLANTAÇÃO DE SISTEMA DE ANÁLISE DE PERIGOS E PONTOS CRÍTICOS DE CONTROLE EM LACTÁRIO}

\section{DETERMINATION OF HAZARDS AND CRITICAL CONTROL POINTS TO IMPLANTATION OF HAZARD ANALYSIS AND CRITICAL CONTROL POINT SYSTEM IN LACTARY}

\author{
Míriam Isabel Souza SANTOS
}

Eduardo César TONDO²

RESUMO

\begin{abstract}
Lactários são unidades hospitalares destinadas ao preparo, higienização e distribuição de mamadeiras e seus substitutos destinados a recém-nascidos e demais pacientes da pediatria. O cuidado durante o preparo deste tipo de alimentação deve ser bastante rigoroso, pois a população-alvo, além de apresentar maior suscetibilidade a enfermidades transmitidas por alimentos, pode estar imunologicamente debilitada. O objetivo desse trabalho foi investigar a qualidade microbiológica e os procedimentos de preparação das mamadeiras formuladas no lactário do Hospital de Clínicas de Porto Alegre e, a partir destas análises, elaborar fluxogramas e identificar perigos e pontos críticos de controle para implantação do sistema de Análise de Perigos e Pontos Críticos de Controle neste setor. Em um período de 6 meses, foram analisadas 75 formulações e 18 matérias-primas quanto à quantidade de mesófilos totais, coliformes totais, coliformes fecais, Staphylococcus aureus, Staphylococcus epidermidis, Bacillus cereus, Streptococcus sp., Clostridium sulfito redutores, bolores e leveduras e presença de Salmonella sp. As temperaturas, assim como o tempo de cada etapa das preparações também foram avaliadas. As análises microbiológicas demonstraram que 77,3\% das amostras estavam com qualidade microbiológica insatisfatória segundo os padrões estipulados pela Seção de Dietética Experimental do Hospital das Clínicas de São Paulo. No entanto, nenhuma delas apresentou contaminação por microorganismos patogênicos. As medições de tempo e temperatura demonstraram necessidades de melhorias nas etapas de resfriamento, conservação fria e reaquecimento, enquanto a análise do fluxograma sugeriu como pontos críticos de controle, além dessas etapas citadas, a recepção e estocagem da matéria-prima, a fervura e a cocção. Com base nestes dados, foram implementadas melhorias em boas práticas de fabricação e a implantação completa do sistema de Análise de Perigos e Pontos Críticos de Controle.
\end{abstract}

Termos de Indexação: unidades hospitalares, alimentos formulados, análise química, análise microbiológica.

\section{ABSTRACT}

Lactaries are hospital facilities where feeding bottles and their substitutes are prepared and distributed for newborn intant and other pediatric patients. The preparation of such kind of food must be very

\footnotetext{
1) Instituto Metodista de Educação e Cultura, Hospital de Clínicas de Porto Alegre.

${ }^{(2)}$ Instituto de Ciência e Tecnologia de Alimentos, Universidade Federal do Rio Grande do Sul. Av. Bento Gonçalves, 9500, Prédio 43212, Bairro Agronomia, 91505-970, Porto Alegre, RS, Brasil. Correspondência para/Correspondence to: E.C. TONDO.E-mail: tondo@vortex.ufrgs.br
} 
carefully followed since it is destined to patients who are very susceptible to foodborne diseases. The present work aimed at investigating the microbiological quality and procedures for the preparation of feeding bottles in the lactary of the General Clinics Hospital of Porto Alegre, RS to implement Hazard Analysis and Critical Control Point system. During a six month period, 75 samples of feeding bottle formulations and 18 samples of raw materials were analyzed for the quantity of total mesophiles total and fecal coliforms, Staphylococcus aureus, Staphylococcus epidermidis, Bacillus cereus, Streptococcus spp., Clostridium perfringens, molds and yeasts, and the presence of Salmonella sp. The temperature and the time for each step of the preparations were also evaluated. The microbiological analysis showed that $77,3 \%$ of the samples were not in satisfactory microbiological conditions compared to parameters established by Experimental Dietary Division of General Clinics Hospital of University of São Paulo. However, pathogens were not found in any of the analyzed samples. The evaluation of time and temperatures indicated the necessity of improvements of cooling, cold conservation and reheating. Such steps as well as the reception of raw material and water and milk boiling and cooking were also considered critical control points. Based on such results, good manufacturing practices improvements were established and complete implementation of Hazard Analysis and Critical Control Point system was performed.

Index terms: hospital units, food fortified, chemical analysis, microbiological analysis.

\section{INTRODUÇÃO}

O sistema Análise de Perigos e Pontos Críticos de Controle (APPCC) surge, atualmente, como uma importante ferramenta para a qualidade alimentar (McNab, 1998; National Advisory..., 1998). Seu uso torna-se fundamental, principalmente, nos estabelecimentos onde a preparação de alimentos necessita de rigorosas condições de higiene, como é o caso das Centrais de Sondas e Lactários onde são preparadas dietas enterais e fórmulas lácteas.

\section{(1987) como:}

O lactário foi descrito por Fázio citado por Mezomo,

"Unidade do hospital destinada ao preparo, higienização e distribuição das mamadeiras de leites e seus substitutos, juntamente com água, chá e demais hidratantes, para alimentação de recém-nascidos e dos pacientes da pediatria, sob as mais rigorosas técnicas de assepsia, de maneira a oferecer à criança uma alimentação adequada com menor risco de contaminação".

Tendo em vista seu objetivo e sabendo-se a fragilidade da clientela atendida em um hospital, o controle de qualidade é de fundamental importância, a fim de garantir a inocuidade do produto final.

Alguns trabalhos têm sido desenvolvidos com o objetivo de avaliar a qualidade do produto final em lactários. Pessoa et al. (1978), analisando preparações lácteas no município de São Paulo, constataram a presença de E. coli em $15,80 \%$ das amostras. Salles \& Goulart (1997) analisando as condições microbiológicas de 24 amostras de formulações preparadas em lactários hospitalares em Florianópolis, SC, encontraram 54,16\% das mesmas fora do padrão estabelecido pela Portaria 001/87- Ministério da Saúde na contagem de coliformes totais e 41,60\% das amostras apresentavam condições higiênico-sanitárias insatisfatórias por coliformes de origem fecal. Contudo, não foi encontrado $E$. coli nas amostras analisadas, e em apenas uma delas havia $S$. aureus. Cabe salientar que em relação a mesófilos totais $100,00 \%$ das amostras estavam fora dos padrões.
Tendo em vista a importância da alimentação láctea como coadjuvante, ou, em muitos casos como a medida terapêutica básica em hospitais e a necessidade de se ofertar produtos com qualidade assegurada, desenvolveu-se este estudo, o qual objetivou a determinação de perigos e pontos críticos de controle em lactário, a partir de análises microbiológicas do produto final e matérias-primas e medições de tempo x temperatura nas diferentes etapas de preparação de fórmulas lácteas para posterior implantação do sistema APPCC.

\section{MATERIAL E MÉTODOS}

Este trabalho foi desenvolvido no Hospital de Clínicas de Porto Alegre, Rio Grande do Sul, hospital público que possui 168 leitos para atendimento pediátrico, sendo estes divididos em Unidades de Internação Pediátrica, de Tratamento Intensivo, de Neonatologia e Emergência.

O lactário produz, em média, 1050 fórmulas por dia, incluindo fórmulas lácteas, enterais e hidratantes. As fórmulas são calculadas individualmente, conforme recomendação e hábito alimentar do paciente, não existindo um padrão único.

Durante o período de agosto de 1998 a fevereiro de 1999 foram coletadas, em frascos estéreis, um total de 93 amostras, sendo 25 de fórmulas enterais, 25 de leite de vaca com açúcar ( Lv + aç), 25 de mamadeiras industrializadas e 18 de matérias-primas utilizadas no preparo das fórmulas. As matérias-primas analisadas foram água, leite esterilizado, leite tipo C, leite em pó, leite em pó desnatado, Nan, Alsoy, ProSobee, Soymilke, Novomilke, Alfaré, Pregestimil, Maxijoule, Caseínato CC, Mucilon, Farinha de aveia, Maizena e açúcar refinado.

A pesquisa microbiológica das fórmulas e matérias-primas consistiu da contagem de microorganismos 
mesófilos totais, da determinação do número mais provável de coliformes totais e coliformes de origem fecal pela técnica dos tubos múltiplos, contagem de Staphylococcus aureus, Bacillus Cereus, Clostridium sulfito redutores, bolores e leveduras e presença de Salmonella sp. As análises foram realizadas de acordo com os métodos preconizados pela American Public Health Association (Speck, 1984). Também foram quantificados Staphylococcus epidermidis segundo metodologias descritas por Food and Drug... (1992) e Streptococcus sp. conforme metodologia sugerida por Baron et al. (1994).

Os resultados das análises microbiológicas foram comparados com os parâmetros estabelecidos pela Seção de Dietética Experimental da Divisão de Nutrição e Dietética do Hospital das Clínicas da Faculdade de Medicina da Universidade de São Paulo (Maculevicius \& Gobbo, 1985).

Foram realizadas 90 medições de tempo e temperatura em cada uma das etapas de preparo, cocção, resfriamento, conservação à frio, reaquecimento e distribuição. Também foram medidas as temperaturas da água e leite utilizados nas formulações.

A medição de temperatura foi realizada com termômetro digital tipo baioneta com precisão de duas casas decimais (marca Stem), colocando-se o mesmo no centro geométrico da preparação. O tempo foi mensurado com cronômetro digital. Os dados foram anotados em planilhas para análise posterior.

De posse das informações, obtidas nas etapas posteriores, elaborou-se o fluxograma detalhado do processo produtivo e seus respectivos Pontos Críticos de Controle (PCC).

\section{RESULTADOS E DISCUSSÃO}

Não foi evidenciada a presença de Staphylococcus aureus, Bacillus cereus, Salmonella e Clostridios sulfito redutores nas amostras de leite de vaca com açúcar, mamadeira industrializada e fórmula enteral. A ausência desses microorganismos é fundamental em fórmulas lácteas, tendo em vista o estado imunológico dos pacientes (Tabelas 1, 2 e 3). Sessa \& Furlanetto (1990), analisando as condições bacteriológicas de lactários em São Paulo, constataram que $5 \%$ das amostras estavam contaminadas por $S$. aureus. Tais microorganismos são freqüentemente encontrados em manipuladores e evidenciam perigo potencial de intoxicação alimentar (Jay, 1996).

Soares et al. (1997) encontraram S. aureus multiresistentes à antibióticos e produtores de enterotoxinas nas mãos de manipuladores de alimentos de hospitais em Teresina no Piauí. Waldvogel (1999) descreveu casos de infecção por $S$. aureus resistentes à vancomicina veiculados por alimentos servidos em Unidade de Tratamento Intensivo hospitalar. Ressalta-se a importância de cuidados constantes com os manipuladores de alimentos em ambientes hospitalares, pois os mesmos podem ser veículos de transmissão não apenas de $S$. aureus, mas de diversos microorganismos patogênicos.

Todas as amostras analisadas (Tabelas 1, 2 e 3) não apresentaram contaminação por coliformes fecais, sugerindo Boas Práticas de Fabricação (BPF) em relação a higiene de manipuladores e ambiente de trabalho. Salles (1997) analisando preparações lácteas no município de Florianópolis, SC, constatou que $41,6 \%$ das amostras apresentavam contaminação por coliformes fecais. A pesquisa de coliformes fecais nos alimentos fornece informações sobre as condições higiênicas do produto e melhor indicação da eventual presença de enteropatógenos (Franco, 1996).

As fórmulas lácteas e enterais foram comparadas com os parâmetros estabelecidos pela Seção de Dietética Experimental da Divisão de Nutrição e Dietética do Hospital das Clínicas da Faculdade de Medicina da Universidade de São Paulo, a qual preconiza que em fórmulas lácteas a contagem de bactérias deve ser inferior a $100 / \mathrm{ml}$, coliformes devem estar ausentes em $1 \mathrm{ml}$, bolores e leveduras inferiores $10 / \mathrm{ml}$, Bacillus cereus menos de $100 / \mathrm{ml}$, S. aureus e Clostridrium sulfito redutores ausentes em $1 \mathrm{ml}$ e Salmonella deve estar ausente em $25 \mathrm{ml}$. Para fórmulas enterais determinam a contagem de bactérias mesófilas e classificam como ótimas amostras com zero a $10^{2} \mathrm{UFC} / \mathrm{ml}$, boas amostras com $10^{2}-10^{3} \mathrm{UFC} / \mathrm{ml}$, vigilância sobre amostras com $10^{3}-10^{4} \mathrm{UFC} / \mathrm{ml}$ e amostras que apresentam risco por apresentarem $>10^{5} \mathrm{UFC} / \mathrm{ml}$. Tais parâmetros também estipulam que coliformes totais e fecais, Bacillus cereus, bolores e leveduras devem estar ausentes em $1 \mathrm{ml}$ e Salmonellas ausentes em 25 ml (Maculevicius \& Gobbo, 1985).

Analisando a Tabela 1 referente a análise de Lv + aç, observa-se que 21 amostras (84,00\%) apresentaram condições higiênico-sanitárias insatisfatórias quando comparadas ao padrão acima citado. Dessas, 11 (44,\%) apresentavam-se com contagens de mesófilos totais maiores que 100/ml, 8 (32\%) evidenciaram presença de coliformes totais e contagem de mesófilos acima de 100/ml, 1 (4\%) apresentavam coliformes totais, bolores e leveduras e bactérias mesófilas acima de 100/ml e 1 (4\%) evidenciou bolores e leveduras e contagem total de mesófilos acima de $100 / \mathrm{ml}$.

Das 25 fórmulas de mamadeiras industrializadas analisadas, 20 (80\%) encontraram-se fora dos padrões estabelecidos. Dessas, 14 (56\%) apresentaram contagens de mesófilos totais acima de 100/ml, 6 (24\%) evidenciaram contaminação por coliformes totais e bactérias mesófilas acima de 100/ml (Tabela 2). 
Tabela 1. Análises microbiológicas* de fórmulas de leite de vaca com açúcar (Lv + aç) produzidas no lactário do HCPA.

\begin{tabular}{|c|c|c|c|c|c|c|}
\hline \multirow[t]{2}{*}{ Número de amostra } & CTM/UFC & $\mathrm{CT} / \mathrm{NMP}$ & CF/NMP & \multirow{2}{*}{$\begin{array}{c}\text { S. epider midis } \\
\text { UFC/ml }\end{array}$} & \multirow{2}{*}{$\begin{array}{c}\text { Bolores e Leveduras } \\
\text { UFC/ml }\end{array}$} & \multirow[t]{2}{*}{ Streptococcus sp. } \\
\hline & & $\mathrm{ml}$ & & & & \\
\hline 1 & $1,6 \times 10^{3}$ & $5,5 \times 10$ & $<0,03$ & $1,8 \times 10^{2}$ & aus & $3,8 \times 10^{2}$ \\
\hline 2 & $4 \times 10^{2}$ & $2,3 \times 10$ & $<0,03$ & $4 \times 10$ & aus & $3,0 \times 10$ \\
\hline 3 & $1,5 \times 10^{4}$ & $<0,03$ & $<0,03$ & $3,8 \times 10^{3}$ & aus & $2,5 \times 10^{3}$ \\
\hline 4 & $2,9 \times 10^{3}$ & $5,8 \times 10^{2}$ & $<0,03$ & $1,9 \times 10^{3}$ & $1 \times 10^{2}$ & $1,1 \times 10^{2}$ \\
\hline 5 & $4 \times 10^{2}$ & $<0,03$ & $<0,03$ & $2 \times 10^{2}$ & aus & aus \\
\hline 6 & $4 \times 10^{2}$ & $2 \times 10^{2}$ & $<0,03$ & $2 \times 10^{2}$ & aus & aus \\
\hline 7 & $9,1 \times 10^{6}$ & $2,4 \times 10^{3}$ & $<0,03$ & $9,08 \times 10^{4}$ & aus & $9,3 \times 10^{3}$ \\
\hline 8 & $9,5 \times 10^{3}$ & $<0,03$ & $<0,03$ & $2,05 \times 10^{3}$ & aus & aus \\
\hline 9 & $1,4 \times 10^{6}$ & $<0,03$ & $<0,03$ & $1,2 \times 10^{4}$ & aus & aus \\
\hline 10 & $5,5 \times 10^{3}$ & $<0,03$ & $<0,03$ & $8,3 \times 10^{2}$ & aus & aus \\
\hline 11 & $3 \times 10^{2}$ & $<0,03$ & $<0,03$ & $3 \times 10^{2}$ & aus & aus \\
\hline 12 & aus & $<0,03$ & $<0,03$ & aus & aus & aus \\
\hline 13 & $1,8 \times 10^{3}$ & $<0,03$ & $<0,03$ & $12 \times 10^{3}$ & $3 \times 10^{2}$ & aus \\
\hline 14 & $3,1 \times 10^{4}$ & $1,65 \times 10^{4}$ & $<0,03$ & aus & aus & aus \\
\hline 15 & $2 \times 10^{2}$ & $<0,03$ & $<0,03$ & aus & aus & aus \\
\hline 16 & $1,2 \times 10^{6}$ & $3,6 \times 10^{5}$ & $<0,03$ & $1,8 \times 10^{4}$ & aus & $2,2 \times 10^{4}$ \\
\hline 17 & $9,8 \times 10^{5}$ & $3,6 \times 10^{5}$ & $<0,03$ & $2 \times 10^{4}$ & aus & $3,5 \times 10^{4}$ \\
\hline 18 & $3 \times 10^{2}$ & $<0,03$ & $<0,03$ & aus & aus & aus \\
\hline 19 & $1,2 \times 10^{4}$ & $9,6 \times 10^{3}$ & $<0,03$ & aus & aus & aus \\
\hline 20 & $4 \times 10^{2}$ & $<0,03$ & $<0,03$ & aus & aus & aus \\
\hline 21 & $6,5 \times 10^{2}$ & $<0,03$ & $<0,03$ & aus & aus & aus \\
\hline 22 & aus & $<0,03$ & $<0,03$ & aus & aus & aus \\
\hline 23 & aus & $<0,03$ & $<0,03$ & aus & aus & aus \\
\hline 24 & $3 \times 10^{2}$ & $<0,03$ & $<0,03$ & aus & aus & aus \\
\hline 25 & aus & $<0,03$ & $<0,03$ & aus & aus & aus \\
\hline
\end{tabular}

$\mathrm{CTM}=$ Contagem Total de Mesófilos; UFC $=$ Unidade Formadora de Colônia; CT $=$ Coliformes Totais, CF $=$ Coliformes Fecais; aus $=$ ausente em $0,1 \mathrm{ml}$

(*) Nas 25 amostras, os resultados foram ausentes para S. aureus (UFC/ml), Bacillus cereus (UFC/ml), Salmonella sp. (UFC/25ml), Clostridios sulfitos redutores (UFC/ml)

As análises das 25 fórmulas enterais (Tabela 3) evidenciaram 17 amostras (68\%) fora dos padrões estabelecidos para contagem de mesófilos totais, uma vez que o parâmetro interno do Hospital de Clínicas de Porto Alegre estipulou como aceitáveis aquelas amostras com menos de 100 UFC/ml (classificação ótima). Contudo se as fórmulas enterais analisadas fossem classificadas pelos padrões estipulados pelo Hospital das Clínicas de São Paulo, 7 (28\%) das amostras apresentaram ausência de microorganismos, sendo classificadas como ótimas; 4 amostras (16\%) em condições higiênicas insatisfatórias apresentando coliformes totais e contagem de bactérias mesófilas em valores considerados de vigilância $10^{3}-10^{4} / \mathrm{ml}$ e $3(12 \%)$ amostras com bactérias mesófilas em valores de vigilância $10^{3}-10^{4} / \mathrm{ml}, 2$ amostras $(8 \%)$ com bactérias mesófilas em valores considerados de risco $>10^{5} / \mathrm{ml}$ e 2 (8\%) amostras com bactérias mesófilas em valores considerados de risco $>10^{5} / \mathrm{ml}$ e coliformes fecais.

O somatório de todas as análises apresentadas nas Tabelas 1, 2 e 3 revela que das 75 amostras investigadas $77,3 \% \quad(n=58) \quad$ delas apresentaram qualidade microbiológica insatisfatória segundo os padrões adotados, sugerindo necessidade de maiores cuidados durante a manipulação desses produtos.

Os padrões estabelecidos pela Associação Americana de Hospitais (Associação Americana...., 1983) determinam o limite máximo de 25 bactérias/ml, e ausência de coliformes de origem fecal em fórmulas lácteas. Segundo estes critérios, apenas $16 \%$ das amostras de $\mathrm{LV}+$ aç e das mamadeiras industrializadas e $28 \%$ das fórmulas enterais seriam considerados produtos aceitáveis para o consumo.

Das 40 amostras de fórmulas lácteas analisadas em lactários de São Paulo por Sessa (1990), apenas 9 (22,5\%) foram consideradas de boa qualidade bacteriológica comparando-se ao padrão microbiológico para os leites tipo B, C e reconstituído estipulado pela Portaria 01/87 do Ministério da Saúde. Esses resultados quando comparados ao padrão da Associação Americana de Hospitais revelaram que $37(92,5 \%)$ das amostras de leite analisadas apresentavam-se impróprias.

A contagem total de bactérias é empregada para indicar a qualidade dos alimentos, independente da 
presença de patógenos. Contagem elevada em alimentos é indicativo do uso de matéria-prima contaminada, processamento insatisfatório ou abuso durante o armazenamento em relação ao binômio tempo $\mathrm{x}$ temperatura (Franco, 1996).

A contaminação verificada nas amostras analisadas parece ser proveniente da matéria-prima (Tabela 4) no caso de preparações sem tratamento térmico, ou de equipamentos e utensílios mal higienizados nos quais evidencia-se necessidade de melhorias nas BPF. A análise das amostras (Tabelas 1, 2 e 3) sugere contaminação principalmente de origem ambiental não patogênica, uma vez que não foi evidenciada a veiculação de patógenos como Staphylococcus aureus, Streptococcus sp., Salmonella sp., Bacillus cereus e Clostridios sulfito redutores.

As análises realizadas de $S$. epidermidis e Streptococcus sp., apesar de não exigida pelos padrões escolhidos foram realizadas seguindo um padrão interno de qualidade do Hospital de Clínicas de Porto Alegre o qual estipulou aceitabilidade das amostras com $<100$ UFC/ml desses microorganismos.

Segundo esses parâmetros, o Lv + aç apresentaram valores inaceitáveis de $S$. epidermidis e Streptococcus sp. em 13 (52\%) e em 6 amostras (24\%) respectivamente (Tabela 1). Nas mamadeiras industrializadas observou-se S. epidermidis em 12 amostras (48\%) e Streptococcus sp. em 4 amostras (16\%) (Tabela 2). As análises das fórmulas enterais demonstraram 11 (44\%) e 7 (28\%) amostras com contagem inaceitáveis de $S$. epidermidis e Streptococcus sp., respectivamente.

A análise da água utilizada no lactário (Tabela 4) demonstrou a ausência de microorganismos, inclusive coliformes totais e fecais. A ausência desses microorganismos é fundamental no meio de diluição dos demais elementos utilizados nas fórmulas lácteas a fim de garantir a qualidade do produto final.

Tabela 2. Análises microbiológicas* de mamadeiras industrializadas produzidas no lactário do HCPA.

\begin{tabular}{|c|c|c|c|c|c|}
\hline \multirow[t]{2}{*}{ Número de amostra } & CTM/UFC & $\mathrm{CT} / \mathrm{NMP}$ & $\mathrm{CF} / \mathrm{NMP}$ & \multirow{2}{*}{$\begin{array}{c}\text { S. epider midis } \\
\text { UFC/ml }\end{array}$} & \multirow{2}{*}{$\begin{array}{c}\text { Streptococcus sp. } \\
\mathrm{UFC} / \mathrm{ml}\end{array}$} \\
\hline & \multicolumn{3}{|c|}{$\mathrm{ml}$} & & \\
\hline 1 & aus & $<0,03$ & $<0,03$ & aus & aus \\
\hline 2 & $1,64 \times 10^{3}$ & $9 \times 10$ & $<0,03$ & $2 \times 10^{2}$ & $2,6 \times 10^{2}$ \\
\hline 3 & $8 \times 10^{3}$ & $2 \times 10^{2}$ & $<0,03$ & $6 \times 10^{2}$ & $1,5 \times 10^{3}$ \\
\hline 4 & $19 \times 10^{2}$ & $<0,03$ & $<0,03$ & $4 \times 10^{2}$ & $2 \times 10^{2}$ \\
\hline 5 & $3,8 \times 10^{2}$ & $<0,03$ & $<0,03$ & $4 \times 10^{2}$ & aus \\
\hline 6 & $2,24 \times 10^{4}$ & $2,1 \times 10^{3}$ & $<0,03$ & $3 \times 10^{2}$ & aus \\
\hline 7 & $2 \times 10^{2}$ & $<0,03$ & $<0,03$ & $9,8 \times 10$ & aus \\
\hline 8 & $2 \times 10^{2}$ & $<0,03$ & $<0,03$ & $7,5 \times 10$ & aus \\
\hline 9 & $4,2 \times 10^{3}$ & $<0,03$ & $<0,03$ & $8 \times 10^{2}$ & aus \\
\hline 10 & aus & $<0,03$ & $<0,03$ & aus & aus \\
\hline 11 & $2 \times 10^{2}$ & $<0,03$ & $<0,03$ & aus & aus \\
\hline 12 & $8 \times 10^{2}$ & $<0,03$ & $<0,03$ & $4,5 \times 10^{2}$ & aus \\
\hline 13 & $4 \times 10^{3}$ & $4 \times 10^{3}$ & $<0,03$ & aus & aus \\
\hline 14 & $2,5 \times 10^{2}$ & $<0,03$ & $<0,03$ & $2,5 \times 10^{2}$ & aus \\
\hline 15 & $9,6 \times 10^{4}$ & $4,6 \times 10^{4}$ & $<0,03$ & $3 \times 10^{4}$ & aus \\
\hline 16 & $1,5 \times 10^{5}$ & $9,3 \times 10^{4}$ & $<0,03$ & $3,7 \times 10^{4}$ & $5 \times 10^{5}$ \\
\hline 17 & $1,8 \times 10^{2}$ & $<0,03$ & $<0,03$ & aus & aus \\
\hline 18 & $8 \times 10^{3}$ & $<0,03$ & $<0,03$ & $4 \times 10^{3}$ & aus \\
\hline 19 & $6 \times 10^{2}$ & $<0,03$ & $<0,03$ & aus & aus \\
\hline 20 & $1,2 \times 10^{4}$ & $<0,03$ & $<0,03$ & $1 \times 10^{4}$ & aus \\
\hline 21 & aus & $<0,03$ & $<0,03$ & aus & aus \\
\hline 22 & aus & $<0,03$ & $<0,03$ & aus & aus \\
\hline 23 & $2 \times 10^{2}$ & $<0,03$ & $<0,03$ & aus & aus \\
\hline 24 & $5 \times 10^{2}$ & $<0,03$ & $<0,03$ & aus & aus \\
\hline 25 & $6 \times 10$ & $<0,03$ & $<0,03$ & aus & aus \\
\hline
\end{tabular}

CTM = Contagem Total de Mesófilos; UFC = Unidade Formadora de Colônia; $\mathrm{CT}=$ Coliformes Totais, $\mathrm{CF}=$ Coliformes Fecais; aus = ausente em 0,1 $\mathrm{ml}$

(*) Nas 25 amostras, os resultados foram ausentes para S. aureus (UFC/ml), Bacillus cereus (UFC/ml), Salmonella sp. (UFC/25ml), Clostridios sulfitos redutores (UFC/ml) e bolores e leveduras (UFC/ml) 
Tabela 3. Análises microbiológicas* de fórmulas enterais produzidas no lactário do HCPA.

\begin{tabular}{|c|c|c|c|c|c|}
\hline \multirow[t]{2}{*}{ Número de amostra } & CTM/UFC & $\mathrm{CT} / \mathrm{NMP}$ & CF/NMP & epider midis & \multirow{2}{*}{$\begin{array}{c}\text { Streptococcus sp. } \\
\text { UFC/ml }\end{array}$} \\
\hline & \multicolumn{3}{|c|}{$\mathrm{ml}$} & $\mathrm{UFC} / \mathrm{ml}$ & \\
\hline 1 & $1,92 \times 10^{3}$ & $6 \times 10$ & $<0,03$ & $1,5 \times 10^{2}$ & $4 \times 10^{2}$ \\
\hline 2 & $3 \times 10^{2}$ & $<0,03$ & $<0,03$ & $1,8 \times 10^{2}$ & aus \\
\hline 3 & $2,1 \times 10^{5}$ & $<0,03$ & $<0,03$ & $8,2 \times 10^{2}$ & $1,5 \times 10^{4}$ \\
\hline 4 & $3 \times 10$ & $<0,03$ & $<0,03$ & $2,5 \times 10$ & aus \\
\hline 5 & $2 \times 10^{2}$ & $<0,03$ & $<0,03$ & $2 \times 10^{2}$ & aus \\
\hline 6 & aus & $<0,03$ & $<0,03$ & aus & aus \\
\hline 7 & $3 \times 10^{2}$ & $<0,03$ & $<0,03$ & $1,2 \times 10^{2}$ & aus \\
\hline 8 & $3 \times 10^{2}$ & $<0,03$ & $<0,03$ & $9,8 \times 10$ & aus \\
\hline 9 & $5,8 \times 10^{3}$ & $<0,03$ & $<0,03$ & $7,5 \times 10^{2}$ & aus \\
\hline 10 & $3,4 \times 10^{3}$ & $3 \times 10^{2}$ & $<0,03$ & $6 \times 10^{2}$ & $9 \times 10^{2}$ \\
\hline 11 & aus & $<0,03$ & $<0,03$ & aus & aus \\
\hline 12 & aus & $<0,03$ & $<0,03$ & aus & aus \\
\hline 13 & $4,6 \times 10^{3}$ & $<0,03$ & $<0,03$ & $8,1 \times 10^{2}$ & $3,2 \times 10^{3}$ \\
\hline 14 & $5,85 \times 10^{4}$ & $5 \times 10^{2}$ & $<0,03$ & aus & aus \\
\hline 15 & $3 \times 10^{2}$ & $<0,03$ & $<0,03$ & aus & aus \\
\hline 16 & $1,6 \times 10^{5}$ & $9,3 \times 10^{4}$ & $<0,03$ & aus & $1,6 \times 10^{4}$ \\
\hline 17 & $1,8 \times 10^{5}$ & $9,3 \times 10^{4}$ & $<0,03$ & $7 \times 10^{3}$ & $3,5 \times 10^{4}$ \\
\hline 18 & $3 \times 10^{5}$ & $<0,03$ & $<0,03$ & $1,5 \times 10^{5}$ & aus \\
\hline 19 & aus & $<0,03$ & $<0,03$ & aus & aus \\
\hline 20 & $1,5 \times 10^{3}$ & $<0,03$ & $<0,03$ & aus & $2 \times 10^{2}$ \\
\hline 21 & $9,5 \times 10^{4}$ & $9,6 \times 10^{3}$ & $<0,03$ & $1,5 \times 10^{4}$ & aus \\
\hline 22 & $2 \times 10^{2}$ & $<0,03$ & $<0,03$ & aus & aus \\
\hline 23 & aus & $<0,03$ & $<0,03$ & aus & aus \\
\hline 24 & aus & $<0,03$ & $<0,03$ & aus & aus \\
\hline 25 & aus & $<0,03$ & $<0,03$ & aus & aus \\
\hline
\end{tabular}

CTM = Contagem Total de Mesófilos; UFC = Unidade Formadora de Colônia; CT = Coliformes Totais, CF = Coliformes Fecais; aus = ausente em 0,1 ml

(*) Nas 25 amostras, os resultados foram ausentes para S. aureus (UFC/ml), Bacillus cereus (UFC/ml), Salmonella sp. (UFC/25ml), Clostridios sulfitos redutores (UFC/ml) e bolores e leveduras (UFC/ml)

As análises de leite tipo $\mathrm{C}$ e do leite integral encontraram-se dentro dos padrões estabelecidos pela Portaria 451/97 do Ministério da Saúde (Brasil..., 1997). Os demais produtos industrializados analisados não evidenciaram presença de patógenos e todos foram considerados produtos aceitáveis para o consumo quando comparados ao seu padrão específico ou aos valores estabelecidos para produtos a serem consumidos após a adição de líquido, sem emprego de calor, pela portaria acima citada, a qual foi utilizada uma vez que não existe legislação específica para cada formulado.

Cabe ressaltar que mesmo dentro de padrões aceitáveis por lei, a contagem total de mesófilos em determinados produtos foi alta, podendo influenciar a qualidade de produtos sem tratamento térmico.

Na etapa de pesagem, observa-se uma variação de tempo mínimo de 4 a 13 segundos e máximo de 15 a 60 segundos nas 3 fórmulas lácteas analisadas. Os ingredientes em pó utilizados nas formulações foram pesados sobre um guardanapo de papel em uma balança eletrônica, sendo recobertas por este guardanapo e ficando sobre uma bancada de aço inoxidável até o preparo. O tempo mínimo de espera verificado foi de 2 minutos ( $L v+$ aç e mamadeira industrializada) e 4 minutos para a fórmula enteral, enquanto o tempo de espera máximo foi de 70, 76 e 77 minutos para as três preparações avaliadas, respectivamente. Nesta etapa ressalta-se a importância das boas práticas de fabricação em relação a uma adequada higienização de bancadas, utensílios, bem como manipuladores a fim de não permitir veiculação de microorganismos na matéria-prima por manipulação inadequada.

A partir da fervura do leite pasteurizado (Tabela 5) e da água (Tabela 6), a temperatura destas matérias-primas decai para valores mínimos de 29,6C e máximo de $77,5^{\circ} \mathrm{C}$ no leite e valores mínimos de 45,4 드 e máximo de 99C para a água.

A etapa de preparo de fórmulas não cozidas ( $\mathrm{Lv}+\mathrm{aç})$ e a fórmula enteral levaram um tempo mínimo de 15 segundos e máximo de 3 minutos (Tabelas 5 e 7), sendo 
envasados à temperatura mínima de $29,1^{\circ} \mathrm{C}$ e máxima de $70,4^{\circ} \mathrm{C}$ para mistura de $\mathrm{Lv}+$ aç e 46 e $81,1^{\circ} \mathrm{C}$ para a $f^{\prime}$ órmula enteral. A mamadeira industrializada que sofreu processo de cocção teve um preparo de no mínimo 1 minuto e máximo 5 minutos alcançando a temperatura mínima de 76,3ํㅡ e máxima de 99,9ํ․ Arruda (1998) estabelece que na cocção, as fórmulas devem atingir a temperatura de $74^{\circ} \mathrm{C}$, por pelo menos 15 segundos, sugerindo estar adequado o processamento das mamadeiras analisadas.

Após preparadas, as fórmulas lácteas já envasadas foram colocadas em galheteiros e ficaram sobre um balcão em processo de resfriamento que levou o tempo mínimo de 5 minutos (Tabela 6 - mamadeira industrializada) e máximo de 88 minutos (Tabela 7 - fórmula enteral) atingindo uma temperatura final mínima de 29,1ํㅡ e máxima de $51,7^{\circ} \mathrm{C}$ para o $\mathrm{Lv}+$ aç, mínima de $27,6^{\circ} \mathrm{C}$ e máxima de $64^{\circ} \mathrm{C}$ para a fórmula enteral e mínima de $38^{\circ} \mathrm{C}$ e máxima de $90,7^{\circ} \mathrm{C}$ para a mamadeira industrializada.

Durante a manipulação das fórmulas o tempo de exposição à temperatura de risco, (entre 10 e $60^{\circ} \mathrm{C}$ ), deve ser, no máximo, 30 minutos. No resfriamento, as fórmulas devem ser resfriadas na água corrente fria, o que deve promover a redução da temperatura do alimento a $21^{\circ} \mathrm{C}$ em 2 horas e depois no refrigerador $4^{\circ} \mathrm{C}$ em até 4 horas (Arruda, 1998).

Uma vez resfriadas, estas fórmulas são armazenadas em geladeira para serem distribuídas no próximo turno. $\mathrm{O}$ armazenamento das fórmulas lácteas foi feito em refrigerador na própria sala de preparo e o tempo médio de estocagem foi de no mínimo 8 horas e no máximo de 18 horas a uma temperatura que atingiu em média valores mínimos de $3,8^{\circ} \mathrm{C}$ para mamadeira industrializada (Tabela 6) e máximo de 8,9C para Lv + aç (Tabela 5). Maculevicius \& Gobbo (1985) estabeleceram que a estocagem deve ser feita em geladeira, de zero a $8^{\circ} \mathrm{C}$, por período máximo de 24 horas para mamadeiras e 12 horas para fórmulas enterais. Arruda (1998) define o prazo de validade para as fórmulas com autoclavagem terminal como 24 horas no máximo, ou de 12 horas para as que não forem autoclavadas, sendo a temperatura de armazenamento de $4 \stackrel{\circ}{ }$, no máximo.

O reaquecimento das fórmulas lácteas foi realizado em banho-maria por um tempo mínimo de 30 minutos e máximo de 70 minutos para as três fórmulas, atingindo temperaturas mínimas de $28,7^{\circ} \mathrm{C}, 28,4^{\circ} \mathrm{C} \mathrm{C}$ e $30,2^{\circ} \mathrm{C}$ ( $\mathrm{Lv}+$ aç, mamadeira industrializada e fórmula enteral) e máximas de $60^{\circ} \mathrm{C}, 58,7^{\circ} \mathrm{C}$ e $60,9^{\circ} \mathrm{C}$ nas três fórmulas, respectivamente. No reaquecimento as fórmulas devem atingir a temperatura de $74^{\circ} \mathrm{C}$ em no máximo 2 horas e permanecer por 15 segundos nessa temperatura (Arruda, 1998). Maculevicius \& Gobbo (1985) recomendam que o reaquecimento seja realizado a $75^{\circ} \mathrm{C}$ no mínimo, por 5 minutos, ou $65^{\circ} \mathrm{C}$ por 15 minutos.

Tabela 4. Análises microbiológicas* de água e produtos industrializados (Matérias-primas) utilizados no lactário do HCPA.

\begin{tabular}{|c|c|c|c|c|c|}
\hline \multirow{2}{*}{$\begin{array}{l}\text { Número } \\
\text { de amostra }\end{array}$} & \multirow[t]{2}{*}{ Produto } & CTM/UFC & $\mathrm{CT} / \mathrm{NMP}$ & CF/NMP & S. epider midis \\
\hline & & \multicolumn{3}{|c|}{$\mathrm{ml}$ ou $\mathrm{g}$} & UFC/ml ou g \\
\hline 1 & Água & aus & $<0,03$ & $<0,03$ & - \\
\hline 2 & Leite integral & $1,8 \times 10^{2}$ & $<0,03$ & $<0,03$ & $1,2 \times 10^{2}$ \\
\hline 3 & Leite Tipo C & $6,5 \times 10^{4}$ & $<0,03$ & $<0,03$ & $6,5 \times 10^{4}$ \\
\hline 4 & Nan & $1,8 \times 10^{2}$ & $<0,03$ & $<0,03$ & aus \\
\hline 5 & Açúcar refinado & aus & $<0,03$ & $<0,03$ & aus \\
\hline 6 & Alsoy & aus & $<0,03$ & $<0,03$ & aus \\
\hline 7 & ProSobee & $3 \times 10$ & $<0,03$ & $<0,03$ & aus \\
\hline 8 & Soymilke & $7,2 \times 10$ & $<0,03$ & $<0,03$ & $7,2 \times 10$ \\
\hline 9 & Novomilke & $3,2 \times 10^{4}$ & $<0,03$ & $<0,03$ & aus \\
\hline 10 & Leite em pó & $1,2 \times 10^{3}$ & $<0,03$ & $<0,03$ & aus \\
\hline 11 & Leite desnatado & $1,6 \times 10^{4}$ & $<0,03$ & $<0,03$ & aus \\
\hline 12 & Alfaré & aus & $<0,03$ & $<0,03$ & aus \\
\hline 13 & Pregestimil & aus & $<0,03$ & $<0,03$ & aus \\
\hline 14 & Maxijoule & $1,2 \times 10^{2}$ & $<0,03$ & $<0,03$ & $1,15 \times 10^{2}$ \\
\hline 15 & Caseínato & $7,2 \times 10$ & $<0,03$ & $<0,03$ & $6,8 \times 10$ \\
\hline 16 & Mucilon & aus & $<0,03$ & $<0,03$ & aus \\
\hline 17 & Farinha de aveia & $1,5 \times 10^{3}$ & $<0,03$ & $<0,03$ & aus \\
\hline 18 & Maizena & $2 \times 10^{3}$ & $<0,03$ & $<0,03$ & aus \\
\hline
\end{tabular}

CTM = Contagem Total de Mesófilos; UFC = Unidade Formadora de Colônia; CT = Coliformes Totais; CF = Coliformes Fecais; aus = ausente em 0,1 ml

(*) Nas 18 amostras, os resultados foram ausentes para S. aureus (UFC/ml ou g), Bacillus cereus (UFC/ml ou g), Salmonella sp. (UFC/25ml ou g), Clostridios sulfitos redutores (UFC/ml ou g), fungos e leveduras (UFC/ml ou g) e Streptococcus sp. (UFC/ml ou g) 
Foi possível verificar que durante o reaquecimento as fórmulas ficaram expostas a temperaturas de risco por um tempo prolongado (até 70 minutos), permitindo possível proliferação de microorganismos patogênicos, devendo esta etapa do processo ser revista.

O tempo máximo de distribuição das três fórmulas avaliadas foi de 40 minutos, sugerindo não haver alto risco de proliferação microbiana em níveis inaceitáveis desde de que o reaquecimento (etapa anterior) seja realizado na temperatura correta. Maculevicius \& Gobbo (1985) recomendam que após o reaquecimento, o consumo seja imediato, atentando-se para a temperatura de $36^{\circ} \mathrm{C}$ ao ministrar as fórmulas, evitando assim desconforto térmico ao consumidor.

Com base nas análises microbiológicas e físicas acima citadas, foi elaborado fluxograma contendo os Pontos de Controle (PC) e os Pontos Críticos de Controle (PCC), das etapas de processamento das fórmulas lácteas cozidas e não cozidas (Figura 1).

Considerou-se a recepção da matéria-prima um PCC, principalmente em fórmulas não cozidas ( $\mathrm{Lv}+\mathrm{aç} \mathrm{e}$ fórmula enteral), tendo em vista não haver nenhuma etapa posterior que leve à destruição de microorganismos. Leonel et al. (1994) enfatizam o efetivo controle na qualidade dos produtos utilizados como matéria-prima devido a impossibilidade de esterilização térmica dos mesmos na maioria dos casos e torna-se fundamental o controle rigoroso por meio de análises microbiológicas e físicas e parcerias com fornecedores visando a garantia da qualidade dos produtos obtidos, bem como a obtenção de laudos que comprovem a qualidade.

A etapa de fervura foi considerada PCC para fórmulas não cozidas uma vez que nesse passo é possível atingir temperaturas capazes de eliminar microorganismos vegetativos.

A etapa de mistura e envase foi considerada ponto de controle, sendo fundamental boas práticas de fabricação em especial para fórmulas não cozidas, onde a atenção deve ser redobrada nos processos de higienização dos utensílios utilizados no preparo com o intuito de evitar contaminação potencialmente perigosa. Nesse sentido, as mamadeiras utilizadas para envase são autoclavadas após higienização, e os frascos de nutrição enteral são recipientes estéreis descartáveis evitando-se a possível contaminação por estes utensílios.

Considerou-se a etapa de cocção, no caso das mamadeiras industrializadas (cozidas), um PCC, pois neste ponto o binômio tempo $x$ temperatura deve ser monitorado constantemente a fim de eliminar com eficiência microorganismos vegetativos.

Tabela 5. Medições mínimas e máximas de tempo x temperatura do leite de vaca com açucar.

\begin{tabular}{|c|c|c|c|c|}
\hline & \multicolumn{2}{|c|}{ Tempo } & \multicolumn{2}{|c|}{ Temperatura ${ }^{\circ} \mathrm{C}$} \\
\hline & Mínimo & Máximo & Mínimo & Máximo \\
\hline Pesagem de ingredientes & 4 seg & $15 \mathrm{seg}$ & - & - \\
\hline Espera & $2 \min$ & $70 \mathrm{~min}$ & - & - \\
\hline Leite pré-mistura & - & - & 29,6 & 77,5 \\
\hline Preparo (mistura e envase) & $15 \mathrm{seg}$ & 30 seg & 29,1 & 70,4 \\
\hline Resfriamento & $12 \min$ & $83 \mathrm{~min}$ & 29,1 & 51,7 \\
\hline Armazenamento & $8 \mathrm{~h}$ & $18 \mathrm{~h}$ & 4,8 & 8,9 \\
\hline Reaquecimento & $30 \mathrm{~min}$ & $70 \mathrm{~min}$ & 28,7 & 60 \\
\hline Distribuição & $1 \mathrm{~min}$ & $40 \mathrm{~min}$ & 28,4 & 55,6 \\
\hline
\end{tabular}

Tabela 6. Medições mínimas e máximas de tempo x temperatura da mamadeira industrializada (fórmula cozida).

\begin{tabular}{|c|c|c|c|c|}
\hline & \multicolumn{2}{|c|}{ Tempo } & \multicolumn{2}{|c|}{ Temperatura ${ }^{\circ} \mathrm{C}$} \\
\hline & Mínimo & Máximo & Mínimo & Máximo \\
\hline Pesagem de ingredientes & $13 \mathrm{seg}$ & $60 \mathrm{seg}$ & - & - \\
\hline Espera & $2 \min$ & $76 \mathrm{~min}$ & - & - \\
\hline Água pré-mistura & - & - & 45,4 & 99,0 \\
\hline Preparo (mistura, cocção e envase) & $1 \mathrm{~min}$ & $5 \mathrm{~min}$ & 76,3 & 99,9 \\
\hline Resfriamento & $5 \mathrm{~min}$ & $75 \mathrm{~min}$ & 38,0 & 90,7 \\
\hline Armazenamento & $8 \mathrm{~h}$ & $18 \mathrm{~h}$ & 3,8 & 8,8 \\
\hline Reaquecimento & $30 \mathrm{~min}$ & $70 \mathrm{~min}$ & 28,4 & 58,7 \\
\hline Distribuição & $1 \mathrm{~min}$ & $40 \mathrm{~min}$ & 22,0 & 58,0 \\
\hline
\end{tabular}


Tabela 7. Medições mínimas e máximas de tempo x temperatura das fórmulas enterais.

\begin{tabular}{|c|c|c|c|c|}
\hline & \multicolumn{2}{|c|}{ Tempo } & \multicolumn{2}{|c|}{ Temperatura ${ }^{\circ} \mathrm{C}$} \\
\hline & Mínimo & Máximo & Mínimo & Máximo \\
\hline Pesagem de ingredientes & $10 \mathrm{seg}$ & 57 seg & - & - \\
\hline Espera & $4 \min$ & $77 \mathrm{~min}$ & - & - \\
\hline Água pré-mistura & - & - & 46,8 & 99,0 \\
\hline Preparo (mistura envase) & $1 \mathrm{~min}$ & $3 \min$ & 46,0 & 81,1 \\
\hline Resfriamento & $9 \min$ & $88 \mathrm{~min}$ & 27,6 & 64,0 \\
\hline Armazenamento & $8 \mathrm{~h}$ & $18 \mathrm{~h}$ & 4,8 & 8,8 \\
\hline Reaquecimento & $30 \mathrm{~min}$ & $70 \mathrm{~min}$ & 30,2 & 60,9 \\
\hline Distribuição & $1 \mathrm{~min}$ & $40 \mathrm{~min}$ & 25,8 & 56,3 \\
\hline
\end{tabular}

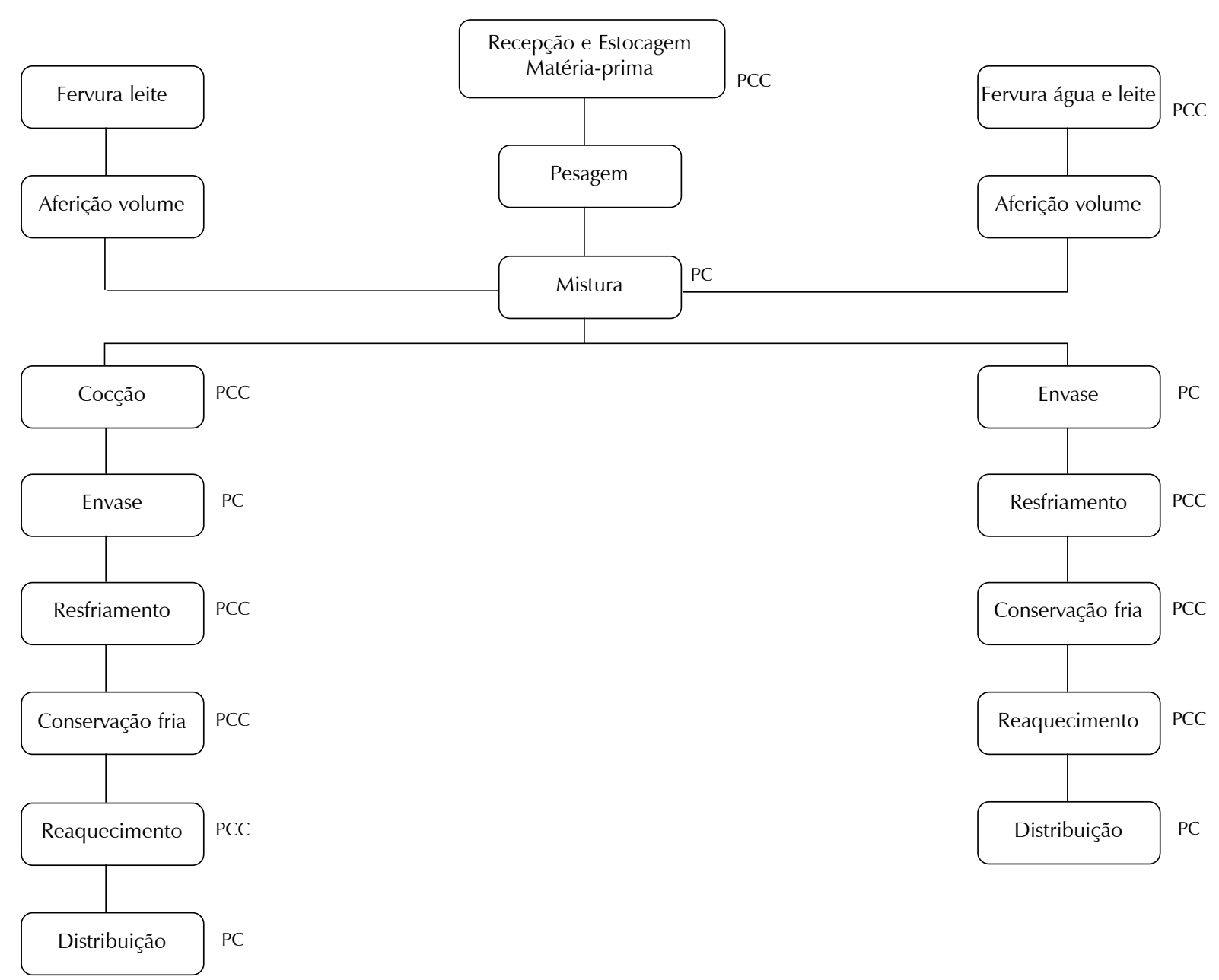

Figura 1. Fluxograma de elaboração de fórmulas lácteas cozidas e não cozidas no lactário do HCPA.

O resfriamento não corresponde a uma etapa planejada na produção das fórmulas lácteas no lactário do HCPA, no entanto ela ocorre na prática e constitui-se um PCC, na medida em que as fórmulas permanecem à temperatura ambiente por até 88 minutos (Tabela 7). Sugere-se abolir esta etapa do processamento ou implementá-la como referendada pela literatura.
A conservação fria das fórmulas lácteas foi considerada como um PCC, pois a temperatura do refrigerador é inadequada $\left(>4^{\circ} \mathrm{C}\right)$ e o grande número de frascos impede a troca de calor necessária, dificultando a rápida refrigeração. Cabe salientar que a abertura constante das portas do refrigerador pode ocasionar oscilações importantes na temperatura interna. Para evitar tal fato as 


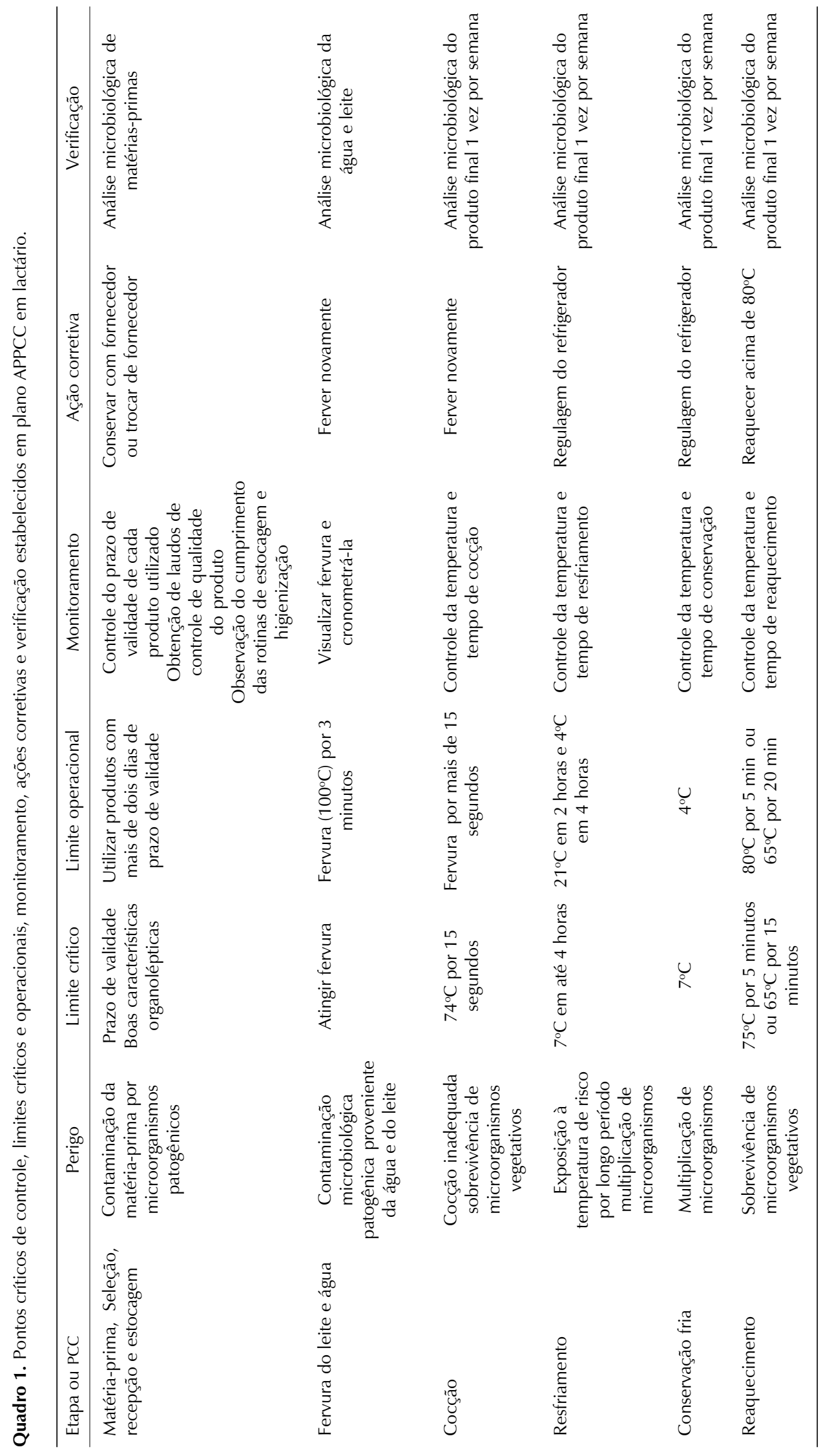

Rev. Nutr., Campinas, 13(3): 211-222, set.,/dez., 2000 
portas são separadas e devidamente identificadas, a fim de evitar aberturas desnecessárias ou prolongadas.

$\mathrm{Na}$ fase do reaquecimento, as fórmulas permaneceram por um tempo de 30 a 70 minutos em temperaturas abaixo do recomendado $\left(74^{\circ} \mathrm{C}\right)$ podendo os esporos sobreviventes de bactérias patogênicas crescer em temperaturas como as apresentadas nas 3 preparações lácteas analisadas. Considerou-se essa etapa PCC devido à temperatura da fórmula submetida ao banho-maria estar inadequada bem como o tempo de permanência. A temperatura do banho-maria deve ser revista, assim como a quantidade de frascos e o espaço entre eles e o tempo de permanência no mesmo.

A distribuição das fórmulas não foi considerada PCC e sim PC porque o intervalo de tempo entre a saída do banho-maria e o consumo do produto não é suficiente para implicar em riscos de ocorrência de perigo, como a multiplicação de esporulados, contudo o tempo de distribuição deve ser o menor possível. Não observaram-se mudanças bruscas nas temperaturas das fórmulas após aquecidas durante a distribuição, confirmando que se a etapa anterior (reaquecimento) for corretamente monitorada se prevenirá o risco de perigo.

Para garantir a segurança do alimento nesta etapa é fundamental a participação de todos os profissionais de saúde que interagem com o paciente. Cuidado deve ser tomado para que não haja contaminação do equipamento (em particular bicos de mamadeiras), por mão de manipuladores, ainda mais sendo a população-alvo bastante suscetível por encontrar-se, na grande maioria, com suas defesas imunológicas debilitadas.

Logo em seguida a identificação de perigos, pontos de controle e pontos críticos de controle, elaborou-se o Quadro 1, onde está representada cada etapa com os perigos correspondentes, as medidas de controle, os limites para cada PCC, o monitoramento dos mesmos e seus métodos de verificações.

\section{CONCLUSÃO}

As análises microbiológicas das fórmulas lácteas realizadas no lactário do Hospital de Clínicas de Porto Alegre demonstraram obtenção de um produto seguro quanto ao aspecto bacteriológico, tendo em vista a ausência de microorganismos patogênicos nas 93 amostras avaliadas. Entretanto, as altas contagens de microorganismos considerados não patogênicos sugerem necessidades de maiores cuidados quanto a qualidade de matérias-primas e BPF durante o processamento. Além disso, as análises físicas e a determinação dos pontos de controle e pontos críticos de controle evidenciaram riscos potenciais a qualidade e segurança das fórmulas oferecidas.

Dessa forma, o sistema APPCC constitui-se em uma ferramenta bastante útil para produção de fórmulas lácteas com qualidade e segurança garantida.

\section{REFERÊNCIAS BIBLIOGRÁFICAS}

ARRUDA, G.A. Manual de boas práticas, São Paulo : Ponto Crítico, 1998. v.2.

ASSOCIAÇÃO AMERICANA DE HOSPITAIS. Funcionamento e planejamento do lactário. São Paulo, 1983.

BARON, E.J., PETERSON, L.R., FINEGOLD, S.M. Diagnostic microbiology. 9.ed. St. Louis : Mosby. 1994. p.338

BRASIL. Portaria n.451 de 19 de setembro de 1997. Dispõe sobre regulamento técnico, princípios gerais para o estabelecimento de critérios e padrões microbiológicos para alimentos. Diário Oficial [da República Federativa do Brasil], Brasília, n.182, p.21005-21011, 22 set. 1997. Seção 1.

FOOD AND DRUG ADMINISTRATION. Bacteriological analitical manual. 7.ed. Airlington : AOAC International, 1992. p.529.

FRANCO, B.D.G.M., LANDGRAF, M. Microbiologia dos alimentos. São Paulo : Atheneu, 1996. p.28-29.

JAY, J.M. Microbiologia moderna de los alimentos. 5.ed. Madrid : Acríbia, 1996. p.431.

LEONEL, M., BURINI, R.C., MACHADO, W.M. Avaliação microbiológica de dietas enterais quando da chegada à enfermaria e da administração aos pacientes. Revista de Metabolismo e Nutrição, Porto Alegre, v.1, p.21-23, 1994.

MACULEVICIUS, J., GOBBO, M.A.R. Manual de organização do lactário. Rio de Janeiro: Atheneu, 1985. p.503-504.

McNAB, W.B. A general framework illustrating an approach to quantitative microbial food safety risk assessment. Journal of Food Protein, v.6 n.9, p.1216-1228, 1998.

MEZOMO, I.F. Lactário. In: MEZOMO, I.F. Serviço de nutrição e dietética. São Paulo : União Social Camiliana, 1987. p.115-137.

NATIONAL ADVISORY COMMITTEE ON MICROBIOLOGICAL CRITERIA FOR FOODS. Hazard analysis and critical control point principles and application guidelines. Journal Food of Protein, v.61, n.9, p.1246-1259, 1998.

PESSOA, G.V.A., CALZADA, C.T., PEIXOTO, E.S., MELLES, C.E.A., KANO, E., RASKIN, M., SIMONSEN, V., IRINO, K. Ocorrência de bactérias enteropatogênicas em São Paulo no septênio 1970 - 1976. III Sorotipos Shigella e Escherichia coli de gastroenterite infantil. Revista do Instituo Adolfo Lutz, São Paulo, v.38, n.92, p.129-139, 1978.

SALLES, R.K., GOULART, R. Diagnóstico das condições higiênico-sanitárias e microbiológicas de lactários hospitalares. Revista de Saúde Pública, São Paulo, v.31, n.2, p.131-139, 1997. 
SESSA, E., FURLANETTO, S.M.P. Condições bacteriológicas de amostras de leite de lactários obtidas em hospitais. Revista de Microbiologia, São Paulo, v.21, n.2, p.189-197, 1990.

SOARES, M.J.S., TOKUMARU-MIYAZAKI, N.H., NOLETO, A.L.S., FIGUEIREDO, A.M.S. Enterotoxin production by Staphylococcus aureus clones and detection of Brazilian epidemic MRSA clone (III:B:A) among isolates from food handlers. Journal of Medical Microbiology, Edinburgh, v.46, p.214-221,1997.
SPECK, M.L. Compendium of methods for the microbiological examination of foods. 2.ed. Washington DC : American Public Health Association, 1984. 914p.

WALDVOGEL, F.A. New resistance in Staphylococcus aureus. New England Jounal of Medicine, Boston, v.340, n.7, 1999. (Editorial).

Recebido para publicação em 21 e junho de 1999 e aceito em 22 de fevereiro de 2000. 